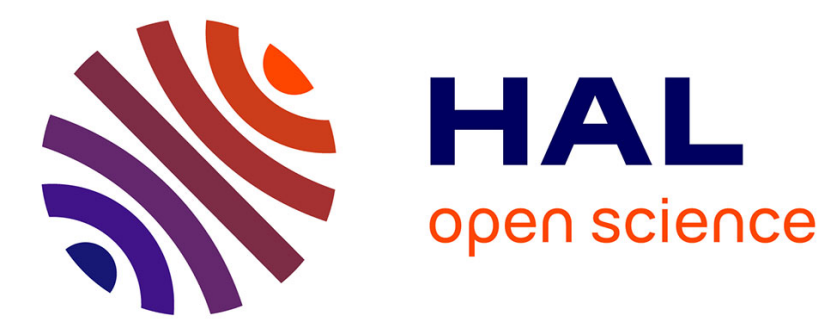

\title{
Entre tribunes et terrain. Les cultures sportives des chefs d'État argentins des années 1880 aux années 1990 Lucie Hémeury
}

\section{To cite this version:}

Lucie Hémeury. Entre tribunes et terrain. Les cultures sportives des chefs d'État argentins des années 1880 aux années 1990. Histoire@Politique: revue du Centre d'histoire de Sciences Po, 2014, 2 (23), pp.97-122. 10.3917/hp.023.0097 . hal-02614099

\section{HAL Id: hal-02614099 \\ https://hal.science/hal-02614099}

Submitted on 20 May 2020

HAL is a multi-disciplinary open access archive for the deposit and dissemination of scientific research documents, whether they are published or not. The documents may come from teaching and research institutions in France or abroad, or from public or private research centers.
L'archive ouverte pluridisciplinaire HAL, est destinée au dépôt et à la diffusion de documents scientifiques de niveau recherche, publiés ou non, émanant des établissements d'enseignement et de recherche français ou étrangers, des laboratoires publics ou privés. 


\section{ENTRE TRIBUNES ET TERRAIN. LES CULTURES SPORTIVES DES CHEFS D'ÉTAT ARGENTINS DES ANNÉES 1880 AUX ANNÉES 1990} Lucie Hémeury

Centre d'histoire de Sciences Po | «Histoire@Politique »

$2014 / 2 n^{\circ} 23$ | pages 97 à 122

Article disponible en ligne à l'adresse :

https://www.cairn.info/revue-histoire-politique-2014-2-page-97.htm

\section{Pour citer cet article :}

Lucie Hémeury, «Entre tribunes et terrain. Les cultures sportives des chefs d'État argentins des années 1880 aux années 1990 », Histoire@Politique 2014/2 (n²3), p. 97-122.

DOI 10.3917/hp.023.0097

Distribution électronique Cairn.info pour Centre d'histoire de Sciences Po.

(C) Centre d'histoire de Sciences Po. Tous droits réservés pour tous pays.

La reproduction ou représentation de cet article, notamment par photocopie, n'est autorisée que dans les limites des conditions générales d'utilisation du site ou, le cas échéant, des conditions générales de la licence souscrite par votre établissement. Toute autre reproduction ou représentation, en tout ou partie, sous quelque forme et de quelque manière que ce soit, est interdite sauf accord préalable et écrit de l'éditeur, en dehors des cas prévus par la législation en vigueur en France. Il est précisé que son stockage dans une base de données est également interdit. 
Lucie Hémeury, « Entre tribunes et terrain. Les cultures sportives des chefs d’États argentins des années 1880 aux années 1990 », Histoire@Politique. Politique, culture, société, n² 23, mai-août 2014 [en ligne, www.histoire-politique.fr]

\title{
Entre tribunes et terrain. Les cultures sportives des chefs d'État argentins des années 1880 aux années 1990
}

\author{
Lucie Hémeury
}

La Coupe du Monde de football de 1978 est restée dans les mémoires, en Argentine et ailleurs, comme le paroxysme de l'instrumentalisation d'un événement sportif au profit du pouvoir en place, en l'occurrence la dictature militaire la plus violente qu'ait connu le pays. Mais l'établissement de relations étroites entre sport et politique remonte au moins au début du $\mathrm{XX}^{\mathrm{e}}$ siècle en Argentine et a été généralement interprétée comme la marque de tentatives d'exploitation de la popularité du sport au service des ambitions des dirigeants politiques. De fait, cette lecture a conduit à faire l'impasse sur la question que nous allons étudier dans cet article, celle de la culture sportive des chefs d'État argentins. En effet, si plusieurs chercheurs en sciences sociales et journalistes sportifs explorent, depuis maintenant une vingtaine d'année, l'histoire du sport en Argentine, la question du rapport personnel au sport des grandes figures politiques a été relativement peu abordée. Le livre d'Ariel Scher, La Patria Deportista, fait figure d'exception ${ }^{1}$.

Cette absence s'explique peut-être parce que la notion de culture sportive reste délicate à appréhender et que dans le cas des hommes politiques, elle n'est apparue que comme un élément relevant de l'anecdotique. De plus, dans le cas des chefs d’État, il a parfois été difficile de distinguer ce qui relevait de la vie intime, des goûts personnels et de stratégies de mise en scène pour construire l'image publique d'un dirigeant sensible aux passions populaires.

Nous nous attacherons donc dans cette étude à distinguer les activités physiques effectivement pratiquées et appréciées par certains présidents argentins et la médiatisation du rapport aux sports, de plus en plus recherchée par les hommes politiques en raison de la popularité croissante du sport dans la société argentine. En ce sens, analyser la culture sportive des chefs d'État argentins, de la fin du XIX ${ }^{\mathrm{e}}$ siècle à la dernière décennie du $\mathrm{XX}^{\mathrm{e}}$ siècle, permet d'éclairer tout un pan de l'histoire culturelle du pays en suivant les transformations du statut du sport et des représentations qui lui ont été associées. Passé d'une pratique réservée à une élite très restreinte à un divertissement de masse, le sport constitue toujours aujourd'hui un pilier de la culture nationale. Mais un examen plus poussé révèle que ce processus s'est accompagné d'une recomposition des cultures sportives : face à la popularisation de certaines pratiques, en premier lieu le football mais aussi la boxe et les courses automobiles, les élites se sont repliées sur des sports restés plus confidentiels, comme

\footnotetext{
${ }^{1}$ Il dresse dans cet ouvrage une série de portraits de grands hommes politiques argentins en se focalisant sur leur rapport au sport. Voir Ariel Scher, La Patria Deportista, Buenos Aires , Editorial Planeta, 1996.
} 
Lucie Hémeury, « Entre tribunes et terrain. Les cultures sportives des chefs d’États argentins des années 1880 aux années 1990 », Histoire@Politique. Politique, culture, société, n² 23, mai-août 2014 [en ligne, www.histoire-politique.fr]

le rugby et le polo, ou fortement associés à des secteurs précis, comme l'escrime ou le tir, liés au milieu militaire. Aussi, à partir de la seconde moitié du XX $\mathrm{X}^{\mathrm{e}}$ siècle, la préférence manifestée par les dirigeants pour certaines disciplines sportives pouvait être interprétée par l'opinion publique comme une prise de position politique, un message signalant l'appartenance idéologique, sociale et culturelle.

Alors que les grandes institutions sportives nationales et le milieu politique ont entretenu une relation presque symbiotique dès les premiers temps de l'implantation et de la diffusion des sports en Argentine, le public argentin s'est souvent montré critique, ou du moins méfiant, à l'égard des rapprochements trop ostentatoires entre la sphère politique et la sphère sportive. Cela s'observe tout particulièrement sous les différentes dictatures militaires qui interrompirent l'ordre démocratique à plusieurs reprises au cours du XX ${ }^{\mathrm{e}}$ siècle. Le stade pouvait ainsi devenir un lieu d'expression du rejet des dirigeants politiques menant des politiques peu favorables aux classes populaires et dont la présence dans une enceinte sportive n'apparaissait pas comme le signe d'une authentique culture sportive mais comme un moyen grossier de s'attirer les faveurs du public.

Comme l'ont montré plusieurs travaux fondateurs, comme la grande synthèse proposée par Victor Lupo ou la thèse de Pablo Alabarces ${ }^{2}$, les lignes de fracture politique, sociale et culturelle s'expriment à travers le sport et les cultures sportives en présence en Argentine. Nous nous proposons de repérer comment les cultures sportives des chefs d'État argentins et surtout leur projection dans l'espace médiatique, entre la fin du XIX ${ }^{\mathrm{e}}$ siècle et les années 1990, permettent de comprendre les logiques à l'œuvre dans les relations entre sphère politique, milieu sportif et opinion publique. Au cours de la première moitié du XXe siècle, plusieurs hommes d'État emblématiques, le radical Marcelo Torcuato d'Alvear et surtout J uan Domingo Perón, ont construit en partie leur popularité et leur image publique à partir du rapport personnel qu'ils entretenaient avec le sport. Un modèle de «président sportif » semble s'esquisser au cours de cette période, mais son identification avec le péronisme lui valut d'être rejeté par les gouvernements suivants, après le coup d'État militaire qui renversa Perón en 1955, avant de réapparaître sous l'ère du ménémisme dans les années 1990.

\section{Le temps des précurseurs (années 1880-1910)}

Le projet politique défendu par les dirigeants de la République dite oligarchique entre les années 1880 et 1910 visait à moderniser et à développer l'Argentine en suivant les principes du libéralisme économique et politique tel qu'il avait été élaboré dans certains pays européens, notamment la Grande-Bretagne et la France, ou aux ÉtatsUnis. Les élites argentines alors au pouvoir admiraient également les formes et pratiques culturelles de ces pays, considérés comme des modèles de civilisation. Le dernier tiers du XIX ${ }^{\mathrm{e}}$ siècle voit donc se produire des circulations et des transferts

\footnotetext{
2 Ces différents auteurs ont proposé des travaux fondateurs sur l'histoire et la sociologie du sport en Argentine : voir Víctor Lupo, Historia política del deporte argentino, Buenos Aires, Corregidor, 2004 et Pablo Alabarces, Fútbol y Patria, Buenos Aires, Prometeo, 2008. Pour une synthèse générale plus récente, consulter Ariel Scher, Guillermo Blanco, J orge Busico, Deporte Nacional. Dos siglos de historia, Buenos Aires, Editorial Planeta, 2010.
} 
Lucie Hémeury, « Entre tribunes et terrain. Les cultures sportives des chefs d’États argentins des années 1880 aux années 1990 », Histoire@Politique. Politique, culture, société, n² 23, mai-août 2014 [en ligne, www.histoire-politique.fr]

culturels intenses de part et d'autre de l'océan Atlantique, fortement encouragés par les dirigeants argentins. Le sport a particulièrement bénéficié de ce contexte. Si les premières pratiques sportives modernes ont été introduites ponctuellement sur les rives du Rio de la Plata dès les premières années du XIX ${ }^{\mathrm{e}}$ siècle, puis de façon régulière à partir des années 1850, l'engouement pour le sport au sein des élites locales fut surtout manifeste à partir des années 1870-1880.

Cette période correspond à la phase de diffusion et d'enracinement des pratiques sportives en Argentine, notamment à travers les premières entreprises d'institutionnalisation menées par les promoteurs du sport. Á l'activité déployée par les membres de la communauté d'immigrés britanniques présente dans le pays ${ }^{3} \mathrm{~s}^{\prime}$ est ajouté le soutien direct apporté par les chefs d'État, les pédagogues et certains représentants des secteurs militaires.

Il est difficile de repérer l'existence d'une véritable culture sportive chez les présidents en exercice de cette époque, comme Carlos Pellegrini ou J ulio Argentino Roca. Leur initiation aux activités physiques était restée limitée au cadre de la préparation militaire et de l'éducation traditionnelle des élites où l'escrime, l'équitation et la pratique du tir restaient des disciplines essentielles pour les officiers et les fils de bonne famille. Néanmoins, ils furent des précurseurs sur plusieurs aspects qui ont caractérisé les relations entre milieu politique et milieu sportif au cours du XXe siècle.

Tout d'abord, ils participèrent à la création et à la vie d'institutions socio-sportives qui jouèrent un rôle fondamental dans la diffusion des sports, comme le J ockey Club, le Círculo de Armas, le Tiro Federal Argentino ou encore la Société hippique argentine. Fondées sur le modèle des clubs anglais, ces sociétés n'avaient pas uniquement une vocation sportive. Leurs objectifs étaient aussi d'ordres économique, commercial et politique. Ainsi, le Jockey Club de Buenos Aires, né en 1882 à l'initiative de Carlos Pellegrini, visait à améliorer l'élevage des chevaux en Argentine, à coordonner les efforts et à défendre les intérêts des grands propriétaires terriens, les estancieros, qui se consacraient à cette activité. L'organisation de concours hippiques et de courses sous le patronage du J ockey Club servait également de vitrine aux progrès réalisés en la matière, en présentant au public les meilleurs représentants issus des haras argentins.

Toutes ces institutions nouvelles apparues au cours des années 1880 étaient à la fois des sociétés d'encouragement, des associations sportives et des cercles de sociabilité réservés aux élites argentines. Elles se présentaient comme des fers de lance du progrès et du développement général du pays, en déployant leur action sur l'ensemble du territoire national. Elles étaient donc étroitement associées aux membres du pouvoir politique en place qui reconnurent la valeur et l'importance de leur rôle en leur accordant des aides financières. Dès 1883, J ulio Argentino Roca, alors au début de son mandat présidentiel, attribua ainsi une subvention de 12000 pesos au J ockey $\mathrm{Club}^{4}$. Il fut, d'après Ariel Scher 5 , le premier chef d'État argentin à verser des fonds publics à une institution sportive, ce qui devint par la suite une pratique courante des

\footnotetext{
3 Fondateurs des premières fédérations et associations sportives dans le pays, comme l'Argentine Association Football League née en 1884 ou la River Plate Polo Association créée en 1892.

${ }^{4}$ Ariel Scher, La Patria Deportista, op. cit., p. 35.

5 Ibid.
} 
Lucie Hémeury, « Entre tribunes et terrain. Les cultures sportives des chefs d’États argentins des années 1880 aux années 1990 », Histoire@Politique. Politique, culture, société, n² 23, mai-août 2014 [en ligne, www.histoire-politique.fr]

présidents argentins. Avant la mise en place d'une véritable politique sportive élaborée par l'État - dans les années 1940-1950 -, les premiers rapports entre pouvoirs publics et associations sportives furent motivés par les préoccupations d'ordre économique.

Julio A. Roca fut également le premier président argentin à assister publiquement à un match de football, le 16 juin 1904, lors d'une rencontre opposant l'équipe locale Alumni aux joueurs britanniques de Southampton. Comme Carlos Pellegrini ou encore J osé Figueroa Alcorta, il fut un contemporain de l'émergence du spectacle sportif, qui se caractérisa par la mise en place progressive d'un cadre spécifique - le terrain, le stade, la piste - et d'un temps spécifique où les spectateurs ne consacraient leur attention qu'au déroulé de l'épreuve ou de la rencontre sportive. Ces hommes politiques furent rapidement sensibles aux nouveaux enjeux posés par le spectacle sportif, en termes de mise en scène du pouvoir, de création de liens avec l'ensemble du public et d'impact médiatique. La présence de Roca dans les tribunes, aux côtés de 12000 spectateurs, s'explique ainsi par la dimension internationale de l'événement et par son caractère exceptionnel, la visite d'une équipe étrangère venue affronter les footballeurs locaux.

La grande majorité de ses successeurs suivit son exemple. J osé Figueroa Alcorta alla même plus loin le 24 juin 1906 en entrant sur le terrain pour prendre dans ses bras Alfredo Brown, auteur du but de la victoire lors du match opposant Alumni à une équipe sud-africaine. Pour la première fois dans l'histoire du football argentin, une équipe locale l'emportait face à des adversaires représentant un pays dépendant de la Couronne britannique ${ }^{6}$. Ce geste traduisait bien l'importance symbolique accordée dès cette époque à ce genre d'événement sportif7. Les dirigeants de la République oligarchique saisirent les possibilités offertes par le sport en termes de projection nationale et de relations diplomatiques. Par exemple, dans le cadre de sa politique de rapprochement avec les pays voisins, Julio Argentino Roca institua un trophée de football à son nom, la Copa Roca, disputée entre des équipes représentant le Brésil et l'Argentine à partir de 1914.

Dès cette période, plusieurs figures politiques de premier plan restèrent donc fortement associées à l'expansion des activités sportives en Argentine alors que celles-ci n'étaient encore qu'une pratique réservée aux secteurs de l'élite. Du fait de son origine britannique, le sport était un objet culturel porteur de modernité et d'une stratégie de distinction pour les classes aisées, fortement attirées par les modèles culturels européens. Certains aspects fondamentaux qui vont caractériser le milieu sportif argentin, ses liens avec l'Etat et les contours de la culture sportive locale apparurent donc sous la République conservatrice.

\footnotetext{
${ }^{6}$ Ariel Scher, La Patria Deportista, op. cit., p. 11.

7 Ce geste est d'ailleurs reproduit par Juan Domingo Perón le 14 mai 1953 lors de la victoire de la sélection argentine sur une équipe anglaise dans le stade de River Plate : devant 85000 spectateurs, le président prit dans ses bras Ernesto Grillo, auteur du doublé qui permit à son équipe de l'emporter.
} 
Lucie Hémeury, « Entre tribunes et terrain. Les cultures sportives des chefs d’États argentins des années 1880 aux années 1990 », Histoire@Politique. Politique, culture, société, n² 23, mai-août 2014 [en ligne, www.histoire-politique.fr]

\section{Marcelo Torcuato de Alvear : le sportsman devenu président}

L'année 1916 correspond à une rupture politique nette en Argentine. Lors des premières élections au suffrage universel masculin, le leader de l'Union civique radicale (UCR), Hipólito Yrigoyen, est élu président de la République. Son parti défendait les droits des classes moyennes et populaires, en prônant des politiques en rupture avec l'ordre conservateur précédent. Les années 1920 furent particulièrement marquées par des transformations rapides de la société argentine, du fait de l'intégration politique de nouveaux secteurs et de l'entrée dans la société des loisirs et la culture de masse. Ce phénomène s'observe tout particulièrement dans la popularisation de certaines disciplines sportives, notamment le football, la boxe et les courses automobiles, et du spectacle sportif, relayé de façon croissante par les médias $^{8}$. Dans ce contexte, il est particulièrement significatif qu'entre 1922 et 1928, le successeur d'Hipólito Yrigoyen à la tête de l'État argentin, le radical Marcelo Torcuato de Alvear, ait été un fervent adepte des sports. Prototype même du sportsman, il incarne en quelque sorte la liaison entre les dynamiques à l'œuvre au cours de la première phase de diffusion des sports et celles qui marquèrent la période 1920-1930.

En effet, du fait de son origine sociale et de ses cercles d'appartenance, il s'inscrivait dans la continuité des précurseurs qu'avaient été Julio Argentino Roca et Carlos Pellegrini. Né en 1868 dans une famille très riche et de lignée ancienne, Alvear faisait partie de la jeunesse dorée de Buenos Aires. Sa génération connut directement l'essor des activités sportives au sein des élites argentines et internationales et lui-même prit part précocement à l'avant-garde sportive du pays. Membre du J ockey Club - son père faisait partie des membres fondateurs - et du Círculo de Armas, Alvear fut un parfait représentant de la culture sportive développée au sein de la haute société argentine, qui reposait à la fois sur des pratiques associées à l'héritage aristocratique, composant le bagage élémentaire que devait posséder un caballero ${ }^{9}$, et sur le modèle du gentleman sportif britannique.

Marcelo T. de Alvear s'essaya ainsi à de nombreuses disciplines et se distingua notamment comme escrimeur et comme excellent tireur. Mais il resta surtout dans les annales sportives du pays comme l'un des pionniers des sports automobiles. Il fut l'un des premiers à importer une automobile à vapeur, appelée Locomovil, pour circuler dans les rues de Buenos Aires, un engin qu'il était capable - et souvent contraint - de réparer lui-même. Si l'usage d'une automobile intriguait déjà les porteños ${ }^{10}$ étant donné que vers 1900 seules neuf automobiles avaient été importées en Argentine, il se fit également remarquer en participant à la première course organisée dans la capitale, dans l'enceinte de l'Hippodrome Belgrano, en 1900 ou 1901. Outre l'équitation, l'escrime, le tir, la natation, le yachting, la boxe et les

\footnotetext{
${ }^{8}$ Le premier magazine entièrement consacré au sport, El Gráfico, voit lejour en 1919, tandis que tous les quotidiens, qui voient leurs tirages augmenter de façon exponentielle, consacrent de plus en plus d'espace aux rubriques sportives.

9 « Gentilhomme » en espagnol.

${ }^{10}$ Nom donné aux habitants de Buenos Aires.
} 
Lucie Hémeury, « Entre tribunes et terrain. Les cultures sportives des chefs d’États argentins des années 1880 aux années 1990 », Histoire@Politique. Politique, culture, société, n² 23, mai-août 2014 [en ligne, www.histoire-politique.fr]

courses automobiles, il expérimenta en France les sports aériens en faisant des voyages en ballon. Par contre, il semble n’avoir jamais joué au football.

Le cas de l'escrime, qui perdait alors de son importance sur le plan militaire, est un bon exemple de pratique dont la valeur sociale restait toujours très forte. Elle s'exprimait en particulier dans le duel, dont Alvear était friand, qui constituait un moyen de règlement des conflits individuels encore largement employé à cette époque ${ }^{11}$. Se battre en duel permettait non seulement de faire preuve de son habileté mais était surtout une démonstration de courage, de virilité et du sens de l'honneur. Avant de devenir président de la nation argentine, Alvear était avant tout connu publiquement comme sportsman. Une fois au pouvoir, il ne cessa pas son activité sportive puisqu'il continua de pratiquer la natation et l'équitation et s'initia au golf. Cela lui fut d'ailleurs reproché : au cours des années 1920, la fonction présidentielle semblait incompatible aux yeux d'une partie de la société avec la pratique des sports, un temps de loisir qui empiétait sur celui qui devait être consacré aux affaires d’État et aux responsabilités qui incombaient au chef del'État.

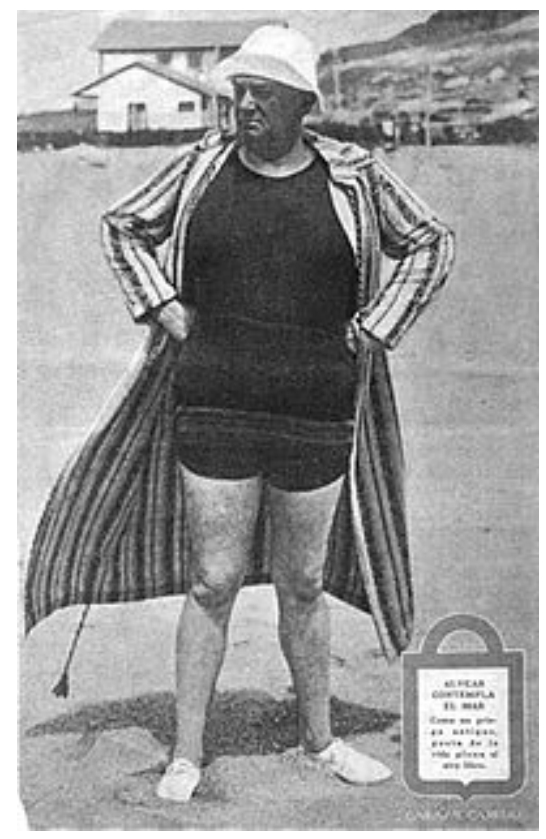

Illustration 1 : Marcelo Torcuato de Alvear en costume de bain, sur la plage de Marc del Plata. La légende indique: «Alvear contemple la mer. Tel un Grec de l’Antiquité, il aime la vie au grand air. » Photographie publiée en 1927 dans la revue Caras et Caretas. (C) Domaine public.

La figure publique de Marcelo T. de Alvear était simultanément celle d'un gentleman sportif, d'un membre de l'élite locale et d'un leader politique d'un parti de masse. Pour cela, il est d'autant plus surprenant qu'il n'ait pas été l'initiateur d'une véritable

\footnotetext{
${ }^{11}$ Pour une histoire de la pratique du duel en Argentine et de ses représentations, voir le livre de Sandra Gayol, Honor y Duelo en la Argentina moderna, Buenos Aires, Siglo XXI Editores, 2008.
} 
Lucie Hémeury, « Entre tribunes et terrain. Les cultures sportives des chefs d’États argentins des années 1880 aux années 1990 », Histoire@Politique. Politique, culture, société, n² 23, mai-août 2014 [en ligne, www.histoire-politique.fr]

politique sportive patronnée par l'État. Il exprimait pourtant régulièrement dans la presse, où il apparaissait très souvent parmi le public assistant à des événements sportifs, son enthousiasme à l'égard des bienfaits du sport. Mais les évolutions expérimentées par le milieu sportif argentin restèrent relativement hors de la sphère d'intervention de l'État : le contrôle du milieu sportif et les innovations introduites dans son organisation et son institutionnalisation dépendaient d'associations, de clubs et de sociétés sportives, soit aux mains de membres des élites, soit issus d'initiatives privées ${ }^{12}$. Le sport n'était pas encore considéré comme un domaine relevant du ressort de l'État.

Dans le même temps, sous les effets de la popularisation, certaines pratiques sportives, notamment le football, cessaient d'être réservées aux élites. S'opéra alors au cours des années 1920 une recomposition du champ sportif, perceptible dans des phénomènes de replis des membres de la haute société autour de sports moins accessibles, pour des raisons économiques, comme le polo ou le golf, ou restés plus confidentiels, comme le rugby. La massification du spectacle sportif, la multiplication des clubs et des associations sportives, l'émergence de sportifs presque professionnels ont entraîné des résistances de la part des premiers promoteurs du sport, extrêmement attachés à l'idéal amateur. Ces derniers craignaient un dévoiement de l'esprit sportif et une corruption de ses fondements originels, sous la pression de nouveaux intérêts économiques.

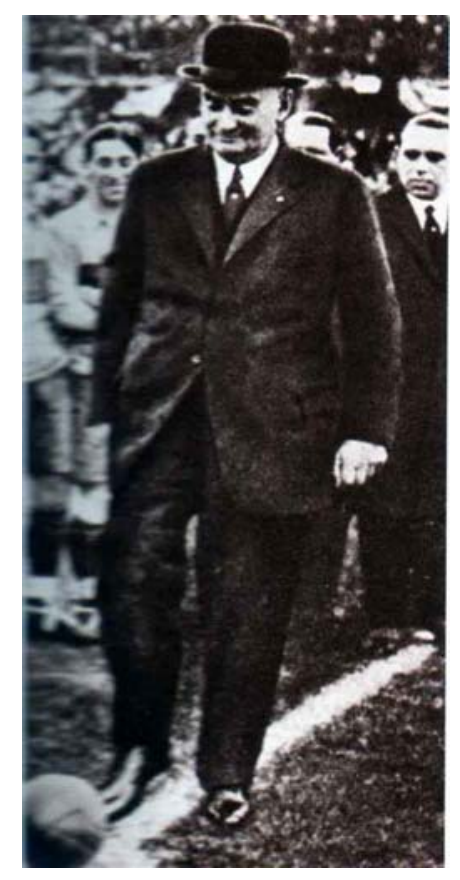

Illustration 2 : Marcelo T. de Alvear donne le coup d'envoi du match amical opposant l'équipe de Boca J uniors à celle du Nacional de Montevideo. Photographie prise lors de

\footnotetext{
12 Concernant l'institutionnalisation du football, consulter J . Frydenberg, Historia social..., op. cit. Pour les autres disciplines sportives, se référer à V. Lupo, Historia política..., op. cit. et A. Scher, G. Blanco et J. Busico, Deporte Nacional..., op. cit.
} 
Lucie Hémeury, « Entre tribunes et terrain. Les cultures sportives des chefs d’États argentins des années 1880 aux années 1990 », Histoire@Politique. Politique, culture, société, n² 23, mai-août 2014 [en ligne, www.histoire-politique.fr]

l'inauguration du stade du club Boca Juniors et publiée dans le journal Crítica, le 7juillet 1924. (C) Domaine public.

À ces critiques, s'ajoutaient les débats encore très vifs entre médecins, hygiénistes, pédagogues et hommes politiques concernant les effets du sport et son intégration au sein de l'institution scolaire ${ }^{13}$. L'idée de promouvoir massivement la pratique des différentes activités sportives et de la rendre accessible à l'ensemble de la population ne s'était pas encore imposée parmi les dirigeants politiques. En outre, les différentes méthodes de gymnastique paraissaient bien plus appropriées, puisqu'elles permettaient d'adapter les exercices à la physiologie de chaque individu, en particulier pour ceux considérés comme «faibles » ou « fragiles », c'est-à-dire les enfants et les femmes ${ }^{14}$.

Ces différents phénomènes expliquent peut-être aussi pourquoi l'action de Marcelo Torcuato de Alvear est restée limitée à des mesures ponctuelles, comme la création du Comité olympique argentin en 1923, qui permit d'envoyer pour la première fois en 1924 une délégation nationale aux J eux olympiques de Paris. Il se soucia également du contenu des programmes d'éducation physique dans les écoles publiques argentines ${ }^{15}$, mais l'impact de ces politiques resta relativement limité. Néanmoins, ce fut sous son mandat que certaines évolutions du rôle de l'État commencèrent à avoir lieu, notamment dans les rapports entre les associations sportives et le gouvernement. Ainsi, les présidents des deux associations qui, depuis 1919, se disputaient la direction du football argentin, firent appel à Alvear et à son arbitrage dans la résolution du conflit qui les opposait. L'intervention du président déboucha sur la réunion, en 1926, des deux institutions en une seule entité, l'Asociación Amateurs Argentinos de Football.

Cette dernière action lui valut là encore des critiques de la part de ses opposants politiques, qui peuvent s'interpréter comme la manifestation d'une méfiance à l'encontre de l'instrumentalisation politique du sport. L'idéal de neutralité et de pureté du sport occupait une place fondamentale dans la conception défendue par les fondateurs de l'olympisme et les défenseurs de l'amateurisme ${ }^{16}$. Cette idée originelle d'une autonomie totale du sport peut expliquer l'absence de véritables politiques gouvernementales de promotion des activités sportives sous la présidence d'Alvear. Ne traduisait-elle pas aussi l'esprit de classe dont Alvear était issu? Le sport

\footnotetext{
13 Angela Aisenstein a développé dans plusieurs travaux la rivalité existant également entre Armée et École pour imposer leurs modèles de préparation et d'entraînement physique des jeunes en Argentine. Pour plus de précisions, voir notamment Angela Aisenstein et Pablo Scharagrodsky, Tras las huellas de la Educación Física Escolar Argentina. Cuerpo, género y pedagogía.1880-1950, Prometeo, Buenos Aires, 2006.

${ }^{14}$ Les débats entre promoteurs des méthodes de gymnastique et partisans des sports britanniques sont apparus en Europe mais ont aussi été très intenses en Argentine. Pour une synthèse détaillée sur cette question en Europe, consulter Alain Corbin (dir.), Histoire du corps, tomes 2 et 3, Paris, Éditions du Seuil, 2005. Pour une analyse du cas argentin, voir A. Ainsenstein et P. Scharagrodsky, Tras las huellas dela Educación Física..., op. cit.

15 Voir Víctor Lupo, Historia nacional...op. cit., p. 35.

${ }^{16}$ Les sportsmen argentins avaient parfaitement intégré les discours des fondateurs européens du sport moderne et cherchèrent à maintenir le modèle du sport amateur. Pour une discussion de l'évolution des représentations du sport, consulter Georges Vigarello, Du jeu ancien au show sportif. La naissance d'un mythe, Paris, Éditions du Seuil, 2002.
} 
Lucie Hémeury, « Entre tribunes et terrain. Les cultures sportives des chefs d’États argentins des années 1880 aux années 1990 », Histoire@Politique. Politique, culture, société, n² 23, mai-août 2014 [en ligne, www.histoire-politique.fr]

continuait de relever du domaine privé, et certaines pratiques exprimaient une appartenance sociale que les secteurs jusqu'alors dominants de la société voulaient préserver et conserver en tant que marqueur identitaire et culturel propre.

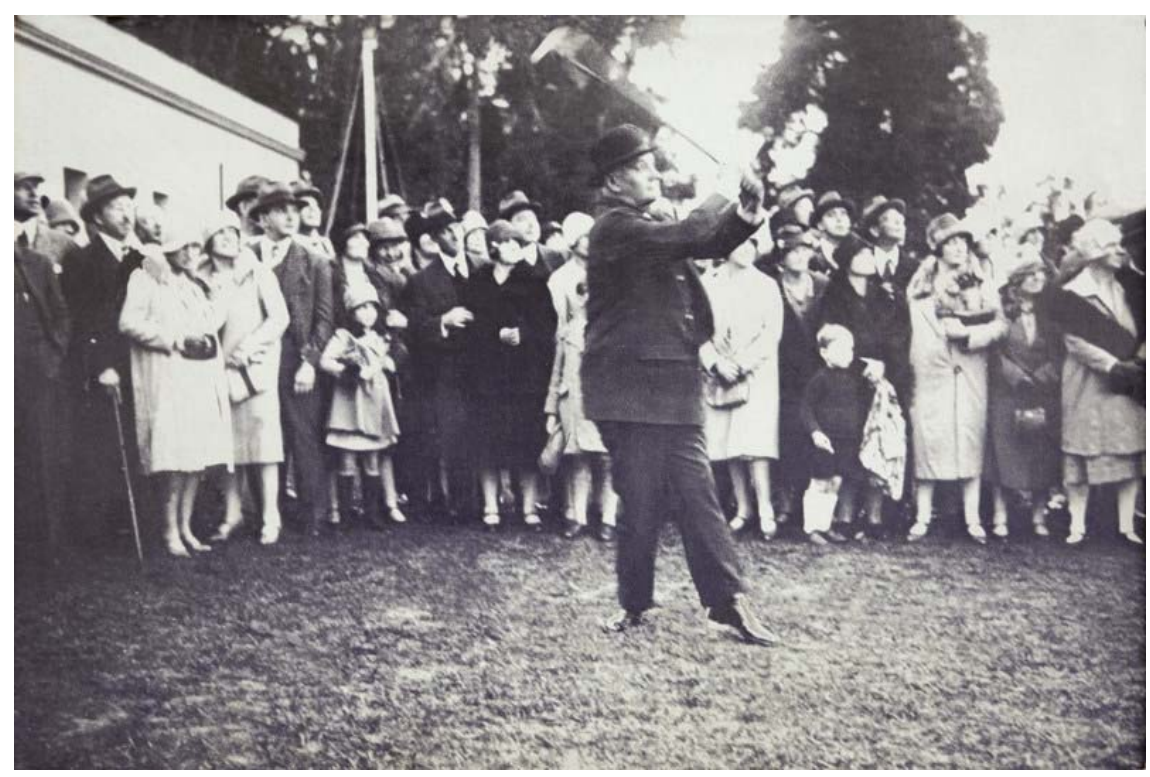

Illustration 3. Un rendez-vous mondain : Marcelo T. de Alvear inaugure les nouvelles installations de l'Olivos Golf Club en frappant la première balle du tournoi de golf. Photographie prise le 19 mai 1928. ㅇ Olivos Golf Club.

\section{Agustín Pedro J usto et le spectacle du sport}

Le général Agustín P.J usto forme, en matière sportive, le chaînon manquant entre Marcelo T. de Alvear et J uan Domingo Perón. Président de la République argentine entre 1932 et 1938, son mandat correspond à ce que l'histoire a surnommé la « décennie infâme », une période marquée par la fraude électorale et les affaires de corruption dans un contexte de grave crise économique. Né lui aussi au sein de la haute société argentine, Agustín P.J usto n'eut qu'une pratique sportive réduite, basée essentiellement sur sa formation militaire. Il maîtrisait l'escrime, savait monter à cheval et s'était initié au basket-ball au cours de ses années d'études au Colegio Militar de Buenos Aires, preuve que l'armée constituait un milieu ouvert aux nouveautés en matière de sport et d'exercices physiques ${ }^{17}$. Il pratiqua également le golf, une activité élitiste dans l'Argentine des années 1930, proposée au sein de clubs prestigieux qui rivalisaient pour compter le président J usto parmi leurs membres.

\footnotetext{
17 Inventé en 1891 aux États-Unis, le basket-ball fut rapidement introduit en Argentine, où il faisait néanmoins figure de sport nouveau par rapport au football ou à d'autres disciplines présentes dès les années 1870.
} 
Lucie Hémeury, « Entre tribunes et terrain. Les cultures sportives des chefs d’États argentins des années 1880 aux années 1990 », Histoire@Politique. Politique, culture, société, n²3, mai-août 2014 [en ligne, www.histoire-politique.fr]

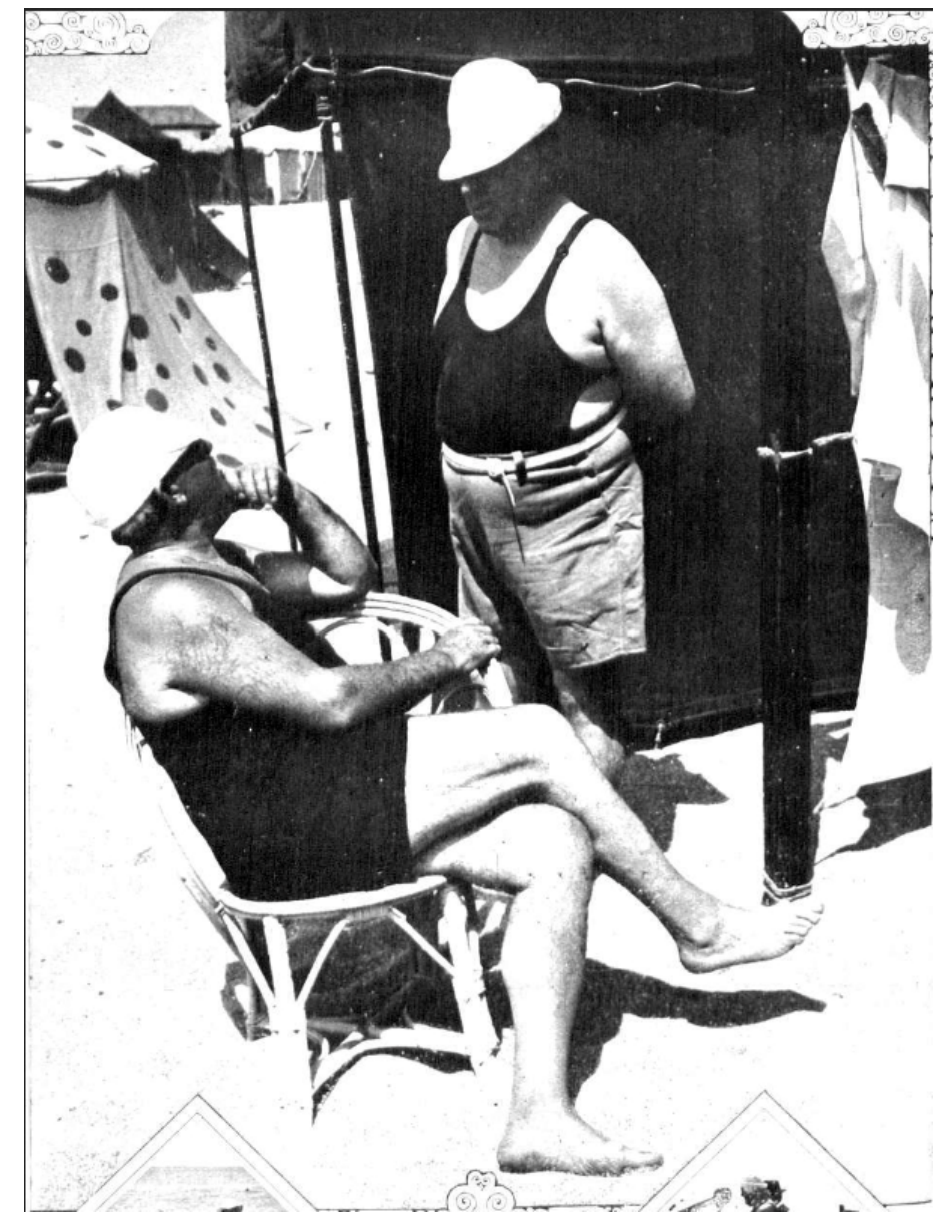

Illustration 4. Agustín P. J usto, en costume de bain dans la station balnéaire de Mar del Plata, discute avec un vacancier. Photographie publiée le 13 février 1932 dans Caras y Caretas. (c) Domaine public.

Justo se différencia de ses prédécesseurs par sa compréhension de "l'énorme incidence sociale du sport [qu'] il essaya d'utiliser et d'amplifier à son profit ${ }^{18}$ ». Ainsi, dès 1932, « il accorde des interviews sur la plage de Mar del Plata, vêtu d'un maillot de bain, offrant l'image d'un homme décontracté qui a le goût de la natation. Ensuite, au cours des six années de son mandat présidentiel, il consacra une partie de son temps à assister à des spectacles sportifs ; et à ce que tout le monde sache qu'il y assistait. ${ }^{19}$ ». J usto appartenait à cet ensemble de chefs d’État des années 1930 qui, en Italie, en Allemagne, aux États-Unis, au Brésil, s'appuyaient politiquement sur les médias et les dynamiques de la société de consommation de masse. J usto comptait parmi ses proches Natalio Botana, le directeur du journal Crítica, l'un des plus populaires de l'époque, caractérisé par ses innovations éditoriales et graphiques. Les

${ }^{18}$ Ariel Scher, La Patria Deportista, Buenos Aires, Planeta, 1996, p. 114.

19 Ibid., p. 124. 
Lucie Hémeury, « Entre tribunes et terrain. Les cultures sportives des chefs d’États argentins des années 1880 aux années 1990 », Histoire@Politique. Politique, culture, société, n² 23, mai-août 2014 [en ligne, www.histoire-politique.fr]

relations entre champ médiatique et milieu sportif ne cessèrent de s'intensifier au cours des années 1930, grâce à l'explosion de la radio qui permit d'amplifier le public sportif, en retransmettant en direct et simultanément dans tout le pays les grandes rencontres sportives. J usto devint un spectateur régulier des événements sportifs mondains, comme les championnats argentins de golf, de polo, les grands prix du turf, les régates internationales de yacht et d'aviron, mais assistait aussi aux spectacles qui rassemblaient les masses populaires comme les courses automobiles et surtout les matchs de football. J usto déploya une stratégie politique coordonnée dont le but était de le présenter comme un défenseur et un promoteur du sport, afin de faire rejaillir sur sa personne la popularité dont jouissait cette activité. Néanmoins, cette stratégie n'était pas toujours fructueuse et le stade se transforma à différentes occasions en un espace de contestation du pouvoir. Son gouvernement qui renouait avec les pratiques de la République oligarchique en excluant une grande partie de la population de la participation politique n'était pas populaire et il lui arriva de se faire huer violemment ${ }^{20}$.

Justo utilisa le sport comme un élément central de son image médiatique, grâce au relais offert par la presse dont les tirages attestent l'ampleur du lectorat à cette époque. En s'appuyant sur ce que ses prédécesseurs avaient initié, il multiplia les actions personnelles pour se rapprocher de l'ensemble des secteurs sociaux à travers le sport : il se rendait au stade pour voir des matchs de football, il donnait le coup d'envoi des rencontres, créait des prix et des coupes portant son nom dans différentes disciplines, cherchait à se lier aux grands sportifs de l'époque et à apparaître à leurs côtés ${ }^{21}$. Mais surtout, et c'est en cela qu'il ouvrit une voie nouvelle aux rapports entre sport et politique et instaura un cadre repris par la majorité de ses successeurs, il s'associa à deux des clubs les plus populaires de Buenos Aires, River Plate et Boca J uniors, et plaça à la tête de l'Association de football argentin (AFA) des personnes de confiance, qui faisaient partie de son entourage direct. À partir de 1937, ce fut même son gendre Eduardo Sánchez Terrero, très lié au club Boca J uniors, qui prit la tête de cette institution devenue, en 1934, la seule entité dirigeante du football professionnel argentin. Comme l'explique Ariel Scher, cette décision offrait des avantages aux deux camps :

«Pour les gouvernements, établir un homme de confiance à ce poste donnait la possibilité de maintenir le football sous leur contrôle. Tandis que pour les dirigeants du football, la concession du trône de l'AFA à quelqu'un de lié aux cimes du pouvoir politique assurait un moyen d'obtenir des faveurs, des subventions ou tous les besoins aux mains des gouvernements et des gouvernants ${ }^{22}$. »

En effet, en l'absence de politique sportive coordonnée des pouvoirs publics, les rapports entre l'État et les institutions sportives se construisirent sur la base de relations personnelles. Les associations se plaignaient régulièrement de l'indifférence des gouvernements à l'égard des activités sportives et de leurs besoins spécifiques,

\footnotetext{
${ }^{20}$ Ariel Scher rapporte ainsi qu'en 1932, lors du Grand Prix Carlos Pellegrini, J usto fut hué par la foule alors qu'il passait en carrosse devant la tribune populaire. Il serait alors descendu et se serait approché des spectateurs, en frappant certains avec son bâton présidentiel. Cette attitude bravache aurait retourné l'attitude du public qui finit par l'applaudir !

${ }^{21}$ A. Scher, La Patria Deportista, op. cit. p. 116-117.

22 Ibid., p. 128.
} 
Lucie Hémeury, « Entre tribunes et terrain. Les cultures sportives des chefs d’États argentins des années 1880 aux années 1990 », Histoire@Politique. Politique, culture, société, n² 23, mai-août 2014 [en ligne, www.histoire-politique.fr]

notamment financiers. Des subventions leur étaient accordées mais de façon très irrégulière et n'avaient aucun caractère systématique. De nombreux sportifs devaient financer par leurs propres moyens leur participation aux J eux olympiques ou à d'autres grandes compétitions internationales, sans pouvoir compter sur leurs fédérations, faute de ressources suffisantes disponibles. Le recours à un intermédiaire, bien placé au sein des cercles politiques, permettaient donc aux institutions sportives d'obtenir plus facilement des sources de financement pour mener à bien leurs projets.

Le football en offre un bon exemple. Eduardo Sánchez Terrero semble bien avoir joué un rôle déterminant dans les stratégies de rapprochement élaborées par les clubs et par J usto lui-même. Après son mandat à la tête de l'AFA, il devint ensuite président de Boca J uniors, club avec lequel J usto renforça ses liens. Il signa notamment un décret autorisant la concession d'emprunts spéciaux pour que les institutions sportives puissent construire des stades. C'est grâce à cette mesure que River Plate et Boca J uniors purent se doter de nouvelles enceintes en 1938 et en 1940. Construites en béton armé, pourvues des installations les plus modernes, ces nouvelles infrastructures monumentales permirent aux deux clubs d'accueillir plus de spectateurs et de consolider leur position dans le paysage sportif de l'époque. J usto, dans le cas de Boca, participa directement aux opérations financières nécessaires à la construction du stade en intégrant la Commission des Finances du club, qu'il présida jusqu'à sa mort. Nommé membre honoraire de River Plate et de Boca J uniors, ce qui était un privilège rare étant donné la rivalité entre ces deux clubs, Justo réussit à mettre en place des relations étroites avec les clubs les plus riches et les plus populaires de l'époque ainsi qu'avec les dirigeants les plus puissants du football. Mais, malgré les hommages rendus par les clubs à sa mort, J usto n'est pas resté dans les mémoires comme un « homme de football » ni comme un grand ami du sport. Il n'est pas parvenu à devenir une personnalité véritablement populaire et son rapprochement avec le sport apparaissait trop clairement comme une manœuvre politique, une instrumentalisation de cette pratique pour tenter de se concilier les bonnes grâces des secteurs de la société qui étaient les premiers à pâtir de sa politique économique et des restrictions à la participation politique.

\section{J uan Domingo Perón, le « Premier Sportif » de la Nation}

L'action de J usto a en outre été éclipsée par la figure de J uan Domingo Perón et les politiques entreprises au cours de ses deux mandats présidentiels, entre 1946 et 1955. L'avènement du péronisme est considéré comme une rupture majeure de l'histoire contemporaine de l'Argentine. Le mouvement politique conduit par Perón et sa célèbre épouse, Eva Perón, a entraîné une redéfinition profonde des lignes de clivage politique, toujours vivaces dans la société argentine actuelle. Le gouvernement péroniste a aussi approfondi et accéléré les transformations sociales et culturelles à l'œuvre depuis les années 1920. Perón s'est notamment démarqué de ses prédécesseurs en devenant le premier président argentin à déployer une véritable 
Lucie Hémeury, « Entre tribunes et terrain. Les cultures sportives des chefs d’États argentins des années 1880 aux années 1990 », Histoire@Politique. Politique, culture, société, n² 23, mai-août 2014 [en ligne, www.histoire-politique.fr]

politique sportive gouvernementale et à faire du sport « une affaire d'État 23 ». S'inspirant des expériences antérieures, il chercha à systématiser les mesures sporadiques proposées par les gouvernements radicaux et conservateurs. La période péroniste se caractérise en effet par une amplification générale du rôle de l'État et de ses sphères d'intervention. Le sport fait partie des domaines qui ont été tout particulièrement touchés par ces nouvelles orientations. L'expression de «fête sportive », proposée par l'historiographie pour qualifier la période péroniste, traduit bien l'impulsion inédite accordée aux sports entre 1946 et 1955.

Perón répondait ainsi en partie aux demandes exprimées par certaines institutions sportives depuis les années 1920-1930, en faisant de l'État un nouvel acteur du champ sportif. Mais, sa politique sportive ambitieuse fut également mise au service de sa stratégie de légitimation politique et de consolidation du régime. Comme Justo avant lui, Perón sut exploiter au mieux les mutations introduites dans la société et la configuration de l'opinion publique par les médias de masse. Plusieurs auteurs ont souligné les liens étroits entretenus entre sphère sportive et milieu médiatique dès l'émergence de l'ère des loisirs et de la société de masse dans les pays occidentaux ${ }^{24}$. Il n'est donc guère surprenant d'observer cette convergence chez J usto puis Perón entre intérêt pour le sport et maîtrise des outils modernes de communication. L'un des objectifs principaux du gouvernement péroniste consista d'ailleurs à établir un contrôle croissant sur la presse, la radio, les actualités cinématographiques, au moyen de la censure, des rachats de groupes d'édition et de stations de radio et de l'expropriation de journaux. La mainmise sur les médias permit de diffuser massivement la propagande élaborée au sein d'un puissant appareil d'État, articulée autour de la valorisation de la figure de Perón. Proclamé « Premier Sportif de la Nation », celui qui était déjà le "Premier Travailleur" de la Nueva Argentina, utilisa constamment son rapport au sport dans la construction de son image publique.

Juan Domingo Perón, comme Alvear, était un sportif accompli. Au cours de ses années d'études au Colegio Militar de Buenos Aires, il s'initia à un grand nombre de disciplines sportives, dont l'escrime, l'équitation, le polo, le basket-ball ou encore la boxe. Ses qualités d'escrimeur - il fut champion militaire d'escrime entre 1918 et 1928 et faillit participer aux J eux olympiques de Paris en 1924 - lui permirent d'entrer en contact avec certains membres de la haute société porteña, une classe sociale à laquelle il n'appartenait pas, en étant admis au sein de la demeure de Carlos Delcasse, qui accueillait un petit cercle très fermé d'amateurs de sports. Outre les liens directs noués avec certaines figures du milieu sportif argentin des années 19201930, Perón eut aussi une expérience de formateur et d'entraîneur sportif au sein de l'armée. $\mathrm{Si}$ au fur et à mesure de son ascension politique, il réduisit sa pratique des sports, il ne cessa jamais de fréquenter assidûment le Luna Park, le temple de la boxe de Buenos Aires et de se passionner pour les courses automobiles. Avec le football, ces deux derniers sports étaient ceux qui rassemblaient le plus grand nombre de spectateurs à l'époque. La culture sportive de Perón et son intérêt authentique à l'égard des activités sportives lui octroyaient, aux yeux d'une grande partie des

\footnotetext{
${ }^{23}$ Ariel Scher, La Patria Deportista, op. cit., p. 185.

24 Consulter notamment le numéro de la revue Le Temps des Médias consacré à l'histoire des rapports entre médias et sports : Patrick Clastres et Cécile Méadel [coord.], Le Temps des Médias. La fabrique du sport, $2007 / 2, n^{\circ} 8$.
} 
Lucie Hémeury, « Entre tribunes et terrain. Les cultures sportives des chefs d’États argentins des années 1880 aux années 1990 », Histoire@Politique. Politique, culture, société, n²3, mai-août 2014 [en ligne, www.histoire-politique.fr]

sportifs et du public, une légitimité incontestable pour mettre en œeuvre une politique sportive et discourir sur les bienfaits du sport. Les médias non seulement rendaient régulièrement compte des apparitions publiques de Perón lors d'événements sportifs mais surtout reproduisirent un très grand nombre de représentations du président en sportif. Perón apparaissait tour à tour en boxeur, en escrimeur, à ski, à cheval, derrière le volant d'une voiture ou sur une moto.

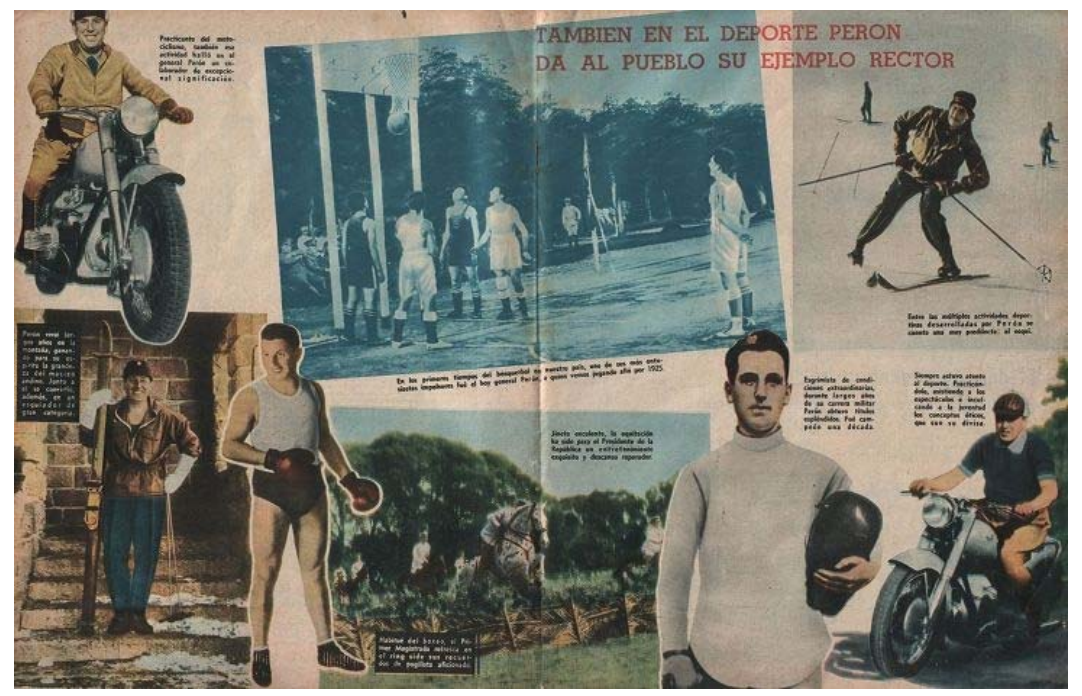

Illustration 5. Exemple de double page faisant l'éloge des aptitudes sportives de Juan Domingo Perón, publiée dans le magazine Mundo Deportivo, en 1953. C Domaine public.

Cette médiatisation du corps du président n'est pas sans évoquer celle qui fut également orchestrée autour de Benito Mussolini par les organes de propagande de l'Italie fasciste ${ }^{25}$. Elle visait à souligner la dimension d"'homme total" attribuée à Perón par la rhétorique péroniste. À travers la mise en scène de ses qualités physiques et athlétiques, le leader péroniste pouvait incarner l'idéal de modernité, de dynamisme et de progrès qui était au coeur de son projet politique pour le pays. J ointes aux nombreux portraits du chef de l'État en compagnie des grands champions de l'époque, ces images servaient également à démontrer et à exalter les vertus personnelles de Perón. Il apparaissait ainsi comme un homme aux goûts simples, proches de ceux du peuple, au caractère franc et direct, facile d'accès, laissant libre cours à ses émotions face aux péripéties d'un match de boxe ou d'une rencontre de football. Ces qualités personnelles étaient censées refléter les qualités politiques du leader et confirmer son caractère de représentant légitime du peuple.

Le péronisme s'est distingué par l'implantation de politiques visant à élargir l'intégration politique et sociale des classes moyennes et populaires. Le sport fut l'un des axes privilégiés par les organismes étatiques et paraétatiques pour inclure des secteurs de la société jusqu'alors restés relativement à l'écart des orientations

25 Voir l'article de Daniele Marchesini, « Corps et pouvoir dans l'Italie fasciste : Mussolini, Carnera et les Italiens », dans Georges Bensoussan, Paul Dietschy, Caroline François et Hubert Strouk, Sport, corps et sociétés de masse. Le projet d'un homme nouveau, Paris, Armand Colin, 2012, p. 93-103. 
Lucie Hémeury, « Entre tribunes et terrain. Les cultures sportives des chefs d’États argentins des années 1880 aux années 1990 », Histoire@Politique. Politique, culture, société, n² 23, mai-août 2014 [en ligne, www.histoire-politique.fr]

gouvernementales. Les enfants, déclarés «les seuls privilégiés » du pays, furent notamment les principaux bénéficiaires de cet ensemble de mesures. Faciliter l'accès aux activités sportives pour l'ensemble de la population et encourager la pratique d'exercices physiques furent présentés comme une conquête sociale, au même titre que la création d'un régime de sécurité sociale ou la mise en place de caisses de retraite et des congés payés.

La création en 1948 des Tournois Evita sous les auspices de la Fondation Eva Perón, dirigée par la Première Dame argentine, et financée par des subventions gouvernementales, fut «l'une des entreprises les plus notables et les plus réussies un moyen supplémentaire de forger la prochaine génération de péronistes ${ }^{26}$. Les Tournois Evita furent l'une des réalisations phares du régime péroniste, celle qui marqua le plus durablement les esprits en Argentine. Elle concentrait toutes les ambiguïtés des politiques péronistes. Pour Raanan Rein, par exemple, ce championnat, qui réunissait en 1954 autour de 216000 filles et garçons de tous le pays concourant dans dix disciplines sportives différentes, devint « une voie supplémentaire permettant la socialisation politique des enfants et des jeunes, une opportunité supplémentaire de faire l'éloge du régime et de mobiliser autour de ses principes le soutien de la jeunesse ${ }^{27} \gg$. S'il est certain que les Tournois Evita étaient l'occasion pour le couple présidentiel d'établir des liens directs avec une grande partie de la population et de prouver leur préoccupation pour le bien-être physique et matériel des enfants, ils avaient aussi une grande signification en termes de politique sociale et sanitaire. Les jeunes participants étaient issus de toutes les régions du pays et découvraient, souvent pour la première fois de leur vie, la capitale. Leur voyage et leur hébergement sur place étaient pris en charge par le gouvernement et la Fondation Eva Perón. Les services de l'État en profitaient pour vérifier que tous les enfants étaient bien inscrits sur les registres d'état-civil et qu'ils disposaient de papiers d'identité. Une visite médicale était aussi organisée avant le tournoi, ce qui permettait de repérer les enfants atteints de certaines maladies comme la tuberculose ou de procéder à des campagnes de vaccination. Les initiatives en matière sportive prises par le gouvernement servaient ainsi de support à des politiques d'intégration nationale et à des campagnes de santé publique de grande ampleur, dont l'impact, pour des catégories de population restées jusqu'alors peu prises en compte par l'État, était tout aussi important.

Néanmoins, cet événement sportif donnait lieu à une mise en scène du pouvoir, en particulier au cours de la cérémonie précédant les épreuves finales. Les enfants défilaient en présence du couple présidentiel et chantaient l'hymne du tournoi, une ode louant Eva Perón et le régime péroniste ${ }^{28}$. Le président et sa femme rencontraient les enfants et échangeaient avec eux, renvoyant ainsi l'image d'un pouvoir accessible, direct et bienveillant. Les antipéronistes dénoncèrent le caractère populiste de ce type de manifestations et la manipulation des masses fomentée à

\footnotetext{
${ }^{26}$ Raanan Rein, «El Primer Deportista. The Political Use and Abuse of Sport in Peronist Argentina, J ournal of the History of Sports, 15:2, p. 54-76, 1998, p. 63.

27 Ibid., p. 65.

28 Voir également Mariano Plotkin, Mañana es San Perón. A Cultural History of Perón's Argentina, Wilmington (Del.), Scholarly Resources, 2003. Il analyse les Tournois Evita dans le cadre du chapitre 8, "The 'Peronization' of Women and Youth".
} 
Lucie Hémeury, « Entre tribunes et terrain. Les cultures sportives des chefs d’États argentins des années 1880 aux années 1990 », Histoire@Politique. Politique, culture, société, n² 23, mai-août 2014 [en ligne, www.histoire-politique.fr]

partir de l'instrumentalisation du sport et de formes d'embrigadement de la jeunesse. Il est certain que ce type d'événements était en permanence relayé par les services de propagande et par les médias étroitement contrôlés par le régime.

Les secteurs de l'opposition critiquaient également l'ingérence grandissante de Perón et des membres du gouvernement dans la conduite du milieu sportif. Dans le prolongement des mesures initiées dès la présidence de Roca et renforcées sous l'ère Justo, Perón fit voter une loi permettant aux institutions sportives de recevoir des subventions publiques et des prêts du gouvernement à des conditions avantageuses. L'État, devenu le principal fournisseur de ressources financières et matérielles, était désormais un interlocuteur essentiel pour les dirigeants sportifs. Il s'ensuivit une situation de soutien réciproque : le milieu sportif rendit régulièrement hommage à Perón et aux membres du gouvernement pour le soutien apporté aux clubs et aux sportifs.

Néanmoins, l'intervention du pouvoir ne se limitait pas à distribuer des fonds publics : tout au long de la période, certaines des institutions sportives les plus puissantes, comme l'AFA ou la Confédération argentine des sports - Comité olympique argentin (CADCOA), furent dirigées par des membres de l'entourage de Perón ou de son épouse. Si le fonctionnement démocratique de ces entités sportives ne fut pas formellement interrompu, il est certain que les circonstances politiques ont encouragé les dirigeants sportifs à élire à leur tête des personnalités proches du nouveau régime en place. De plus, de nombreux sportifs, comme le champion automobile Juan Manuel Fangio ou le boxeur Pascual Pérez, manifestèrent publiquement leur adhésion et leurs remerciements au couple présidentiel. La médiatisation des athlètes péronistes, dont certains étaient de véritables idoles populaires, renforçait l'impression d'un milieu totalement dévoué au régime et soumis à ses impératifs.

Perón cultiva des relations étroites avec les grandes figures sportives de l'époque et s'attacha par ailleurs à faire d'eux des ambassadeurs de la " Nouvelle Argentine » péroniste à l'étranger. Un autre versant de sa politique sportive consista en effet à garantir et à amplifier la participation des athlètes de haut niveau dans les grandes compétitions internationales. Là encore, Perón démontrait sa compréhension des nouveaux enjeux apparus depuis l'entre-deux-guerres, moment où différents événements sportifs, comme les J eux olympiques et la Coupe du Monde de football, allaient devenir des rendez-vous d'envergure mondiale et des lieux de projection des États, représentés par leurs délégations sportives nationales. Les victoires sportives, amplement relayées par les médias de masse, pouvaient s'intégrer aux politiques de relations internationales et de promotion du pays à l'extérieur. Perón n'hésita donc pas à financer les séjours à l'étranger de sportifs argentins, le cas emblématique étant celui de Juan Manuel Fangio qui put, grâce aux subsides fournis par le gouvernement, s'installer en Europe où il devint champion du monde de courses automobiles en 1951, puis quatre fois d'affilée, de 1954 à 1957. Le régime péroniste saisit également l'occasion représentée par les premiers Jeux panaméricains, organisés à Buenos Aires en mars 1951, pour faire de cet événement sportif de grande ampleur une vitrine de la réussite de la "Nouvelle Argentine" péroniste.

La culture sportive de Perón semble bien l'avoir rendu sensible aux possibilités offertes par le sport sur le plan politique. Cela s'est également traduit dans les usages 
Lucie Hémeury, « Entre tribunes et terrain. Les cultures sportives des chefs d’États argentins des années 1880 aux années 1990 », Histoire@Politique. Politique, culture, société, n² 23, mai-août 2014 [en ligne, www.histoire-politique.fr]

rhétoriques du sport auxquels il a régulièrement eu recours, pour exprimer sa conception de la communauté nationale. La nation, comme une équipe de sport collectif, est la réunion d'un ensemble d'individualités agissant de façon coordonnée afin d'atteindre un objectif commun. Dans ce cadre, les vertus associées au sport par les sportsmen - discipline, goût de l'effort, sens du collectif, esprit volontaire depuis la fin du XIX ${ }^{\mathrm{e}}$ siècle étaient particulièrement valorisées par Perón pour leur dimension morale et spirituelle :

«Pour moi, le sport a une signification beaucoup plus grande que celle qu'on lui a attribué jusqu'à présent dans notre pays. J e crois que le sport est une activité créatrice qui complète et renforce l'âme des peuples. Sans le sport, les peuples ne parviennent jamais à perfectionner leur âme comme nous en avons l'ambition pour le peuple argentin ${ }^{29}$.»

Exercice sain auquel tous les Argentins devraient avoir accès, le sport « forge le caractère, trempe l'âme et forme cette nature de vainqueur que doit posséder le citoyen argentin ${ }^{30} \gg$. Si cette perception du sport n'était pas nouvelle, Perón tendait à transformer l'activité sportive en un devoir de tout bon citoyen péroniste et à faire des exploits sportifs un reflet de l'avancée argentine « vers la plénitude de son destin ${ }^{31}$ ». Et Perón, le «Premier Sportif» de la nation, guidait l'Argentine vers cet accomplissement et représentait lui-même un modèle à suivre.

\section{5-1983 : du repli de la culture sportive au paroxysme de l'instrumentalisation du football}

L'empreinte laissée par l'expérience péroniste a fortement pesé sur les chefs d'État qui accédèrent au pouvoir après le renversement de Perón en septembre 1955. Les généraux Eduardo Lonardi et Pedro Eugenio Aramburu, meneurs du coup d'État militaire qui interrompit le dernier mandat de Perón et le contraignit à l'exil, entreprirent une « dépéronisation » générale du pays. Ils s'appliquèrent à effacer toute trace du régime précédent, allant jusqu'à proscrire le parti péroniste et interdire de prononcer les noms de Perón et d'Evita. Plusieurs institutions sportives, dont l'AFA et la CADCOA, passèrent sous le contrôle de la junte militaire et furent « purgées » de leurs éléments péronistes. La junte au pouvoir frappa aussi certains sportifs, qui furent dès lors ostracisés et interdits de stade, pour avoir été des soutiens actifs du régime précédent.

Plusieurs dirigeants sportifs réaffirmèrent alors le principe d'autonomie du milieu sportif et dénoncèrent les pressions politiques subies sous le régime péroniste. Le modèle du sport amateur fut revalorisé par rapport à ce qui était considéré comme des dérives, provoquées par la professionnalisation du sport et l'industrie du sportspectacle. Les idéaux de l'esprit sportif avaient été corrompus sous l'ère péroniste. Les dirigeants de la "Révolution Libératrice", au pouvoir entre 1955 et 1958, mirent

\footnotetext{
29 María Cristina Pons, "Cuerpos sublimes: el deporte en la retórica de la "Nueva Argentina", dans Claudia Soria [et alii], Políticas del Sentimiento. El peronismo y la construcción de la Argentina moderna, Buenos Aires, Prometeo, 2010, p. 49-70, p. 51.

30 Cité dans María Cristina Pons, « Cuerpos sublimes », op. cit., p. 51.

31 Ibidem.
} 
Lucie Hémeury, « Entre tribunes et terrain. Les cultures sportives des chefs d’États argentins des années 1880 aux années 1990 », Histoire@Politique. Politique, culture, société, n² 23, mai-août 2014 [en ligne, www.histoire-politique.fr]

fin à la politique sportive implantée par Perón et supprimèrent les institutions et les compétitions créées par son gouvernement.

Cette réorientation des discours concernant les rapports entre sport et politique explique la faible médiatisation de la culture sportive d’Arturo Frondizi, dirigeant radical élu président de la République en 1958. De crainte d'être identifié à la figure de Perón, le nouveau chef d'État n'exposa jamais publiquement son rapport au sport. Pourtant, Frondizi constitue un personnage intéressant puisqu'il était un homme de football et un représentant de la culture du club. En effet, le club Almagro, fondé en 1911 dans le quartier du même nom à Buenos Aires, fut l'un des espaces clés de ses années de formation ${ }^{32}$. La culture sportive de Frondizi se forgea donc dans un contexte différent par rapport aux présidents évoqués précédemment. Elle se rattache à la sociabilité propre au club de quartier, qui constituait, depuis les années 1920, plus qu'une simple association dédiée à la pratique sportive. C'était aussi un lieu de réunion pour l'ensemble de ses membres et de la population du quartier, un centre culturel où étaient proposées de nombreuses activités, un lieu de rencontre pour les jeunes des rues avoisinantes. Lors des périodes de proscription des partis politiques et de suspension des libertés civiques, par exemple après le coup d'État militaire de 1930, certains clubs sportifs se transformèrent en refuges pour les activités politiques. Frondizi entra ainsi en contact avec le radicalisme en fréquentant le club Almagro, devenu un bastion de l'UCR pendant la "décennie infâme".

La culture sportive de Frondizi, qui pratiqua et apprécia aussi la boxe, resta un domaine limité à sa vie privée. Pour préserver son gouvernement, fragile et qui finit par être renversé par un coup d'État en 1962, Frondizi s'éloigna des méthodes expérimentées par J usto et Perón et ne se rendit jamais au stade voir des matchs, ne félicita jamais publiquement des sportifs, ni ne s'afficha à leurs côtés. La polémique éveillée par le maintien à la présidence de l'AFA de son ami de jeunesse Raúl Colombo, rencontré au sein du club Almagro, démontre que ses craintes n'étaient pas infondées. Les résultats catastrophiques de la sélection argentine de football au Mondial de 1958 rendirent Colombo très impopulaire, mais il parvint à se faire réélire jusqu'en 1965. Frondizi fut soupçonné d'avoir usé de son influence sur les dirigeants des clubs pour conserver cette place à son ancien équipier et compagnon politique.

De même, il évita de mettre en avant l'action de son gouvernement en faveur de l'éducation sportive des enfants. Le gouvernement de Frondizi s'employa à recréer les organes administratifs chargés de cette question. Le président radical chercha également à soutenir le sport de haut niveau en encourageant l'initiative des membres du Comité olympique argentin pour présenter la candidature de Buenos Aires comme siège des J eux olympiques de 1968, projet qui renouait avec un rêve déçu de Perón. Mais, en 1962, Frondizi fut renversé par les Forces Armées qui mirent en place un nouveau gouvernement provisoire militaire, qui se désintéressa totalement de la question et ne permit pas aux délégués argentins de présenter un dossier solide devant la commission du CIO. À l'exception de ces quelques tentatives,

32 Consulter l'article de Matías Rodríguez, "El Presi también juega", disponible en ligne à l'adresse http:// www.sben.com.ar/sben/2013/11/ el-presi-tambien-juega/ [lien consulté le 15juillet 2014]. Il est accompagné d'une photographie d'Arturo Frondizi en footballeur, coiffé d'un béret et entouré de ses coéquipiers du club Almagro. 
Lucie Hémeury, « Entre tribunes et terrain. Les cultures sportives des chefs d’États argentins des années 1880 aux années 1990 », Histoire@Politique. Politique, culture, société, n² 23, mai-août 2014 [en ligne, www.histoire-politique.fr]

le gouvernement radical de Frondizi ne reconstruisit pas de relations entre le milieu sportif et l'État.

Ce désengagement de l'État favorisa probablement la réapparition des tentations d'instrumentalisation directe du sport sous les dictatures militaires qui marquèrent la vie politique argentine des années 1960-1970, et ce malgré les discours appelant régulièrement à la préservation de l'autonomie du sport. De fait, cette autonomie était une illusion entretenue par certains dirigeants : comme au cours des années trente, les clubs et les stades redevinrent des refuges pour les partis proscrits et des lieux d'expression politique sous le régime du général J uan Carlos Onganía. Président de facto entre 1966 et 1970 suite à un coup d'Etat qui renversa le radical Arturo Illia, ce militaire appartenant aux secteurs conservateurs mena plusieurs tentatives malheureuses pour se rapprocher de la population à travers le football. Partisan de la proscription du péronisme, il souhaitait également organiser une remise en ordre morale de la société argentine. Formé au sein des régiments de cavalerie, la culture sportive d'Onganía se limitait essentiellement à la pratique de l'équitation et du polo ${ }^{33}$, soit des disciplines particulièrement identifiées aux secteurs de l'oligarchie et de l'armée. Renouant avec les stratégies initiées par le général Justo, Onganía chercha à associer son image à celle du football, espérant gagner en popularité. Il se rendit au stade du Racing Club d'Avellaneda, qui avait eu des relations très étroites avec le gouvernement péroniste ${ }^{34}$, lors d'un match en 1967 : lorsque sa présence fut annoncée au public par les haut-parleurs, la foule réagit en le sifflant violemment et commença à chanter «Los Muchachos peronistas » en signe de protestation. « Depuis cette soirée, Onganía soigna attentivement ses visites au stade, qu'il réduisit à quelques confrontations internationales et qu'il effectua sans les annoncer à l'avance ${ }^{35}$. » Les stades de football restèrent des lieux d'expression d'hostilité à son égard, loin de la communion recherchée. Déconnecté de la culture footballistique partagée par la majorité de la population, Onganía incarnait en outre l'ennemi de classe aux yeux du public de cette zone populaire de la banlieue de Buenos Aires. Sa présence dans le stade était perçue par les spectateurs comme une opération maladroite de communication politique, voire une provocation.

Si le général Onganía échoua à se concilier les bonnes grâces des audiences sportives, la junte militaire, conduite par J orge Videla, Emiliano Masseri et Orlando Agosti, qui s'empara du pouvoir le 24 mars 1976 y parvint lors de l'organisation de la Coupe du Monde de football en Argentine en 1978. Quelques jours après leur arrivée au pouvoir, les trois dirigeants discutaient des modalités concrètes pour accueillir l'événement. Dès le mois de juillet, l'accueil du Mondial fut décrété « d'intérêt national $^{36}$ ». Contrairement à Onganía, le nouveau régime militaire eut une vision

\footnotetext{
33 Un enregistrement vidéo du président Juan Carlos Onganía s'exerçant au polo est disponible sur le site de Youtube: https:// www.youtube.com/ watch?v=EuGUO9gDJ6k [consulté le 4 mars 2014]. Ces images ont été filmées le 24 septembre 1966 et sont commentées par le célèbre journaliste sportif Eduardo Lorenzo Borocotó.

34 Son stade inauguré en 1951 et construit grâce à des prêts concédés par le gouvernement péroniste, avait été baptisé « Estadio Presidente Perón ». Il fut également surnommé Sportivo Cereijo car le club comptait parmi ses membres et protecteurs attitrés le ministre des Finances de Perón, Ramón Cereijo.

35 Ariel Scher et Héctor Palomino, Fútbol, pasión de multitudes y de elites, Buenos Aires, CISEA, 1989, p. 114

36 Pablo Alabarces, Fútbol y Patria, Buenos Aires, Prometeo, 2008, p. 116
} 
Lucie Hémeury, « Entre tribunes et terrain. Les cultures sportives des chefs d’États argentins des années 1880 aux années 1990 », Histoire@Politique. Politique, culture, société, n² 23, mai-août 2014 [en ligne, www.histoire-politique.fr]

organique de son mode d'exploitation du football, faisant de la Coupe du Monde un objectif quasi militaire, mené en suivant un plan de campagne précis. Si J orge Rafael Videla n'avait qu'une faible relation avec le football, Emilio Massera en était beaucoup plus proche et fut le promoteur le plus actif du maintien du Mondial, malgré la situation économique difficile du pays, peu compatible avec les dépenses à prévoir. La mainmise sur le milieu du football offrait une vaste gamme de possibilités pour un pouvoir en quête de légitimité et d'affirmation. Le football apparaissait comme « un instrument de régulation et de contrôle de la société, un générateur d'éventuelles adhésions politiques, un élément unificateur, un moyen de dissimuler la répression féroce en diffusant une image irénique, un levier pour exacerber le nationalisme, distraire l'attention et faciliter la suppression des dissensions ${ }^{37}$ ». Événement exceptionnel, la Coupe du Monde fut perçue comme une scène où projeter une autre image du régime destinée à la société locale comme aux pays étrangers ${ }^{38}$. Pour ne pas commettre de faux pas et exploiter à plein cette opportunité, la junte fit appel aux services d'une entreprise de communication américaine, spécialisée dans la transformation de l'image gouvernementale. Bien que l'organisation du Mondial fût un gouffre financier pour le régime, la victoire de la sélection argentine permit à la junte d'atteindre certains des objectifs qu'elle s'était fixée, détournant temporairement l'attention de la société argentine et contribuant à consolider son pouvoir.

\section{Menem, un président sur le terrain}

La décennie 1990 est indissociable de la figure de Carlos Menem, président péroniste de 1989 à 1999, qui chercha à renouer avec la figure de Perón tout en menant une politique économique néolibérale outrancière, basée sur la privatisation des entreprises publiques et le démantèlement des acquis sociaux construits par le premier péronisme. Si le bilan de l'ère Menem fut l'objet de vives critiques, le seul domaine où il apparut comme véritablement péroniste semble bien avoir été le sport. Comme Alvear et Perón, Menem fut en effet un sportif enthousiaste, qui s'essaya à de nombreuses disciplines, dont le football, le basket-ball, les courses automobiles ou encore le golf... Il fut notamment un véritable passionné de Formule 1.

Comme J usto et Perón avant lui, Menem rechercha la proximité personnelle et médiatique avec les personnalités sportives les plus notables de la période, de Diego Maradona à Daniel Scioli, champion de courses nautiques, en passant par Carlos Reutemann, pilote de Formule 1. Mais surtout Menem multiplia les apparitions publiques sur les terrains de sport.

\footnotetext{
${ }^{37}$ A. Scher et H. Palomino, Fútbol : pasión de multitudes..., op. cit., p. 147

38 Voir les photographies illustrant plusieurs articles rappelant cet épisode très important de l'histoire de la dictature, publiés suite à la mort de J orge Rafael Videla le 17 mai 2013: Sabrina Faija, "El Mundial 78 : cuando la dictadura puso al fútbol al servicio del terror", Clarín, Buenos Aires, 17 mai 2013, disponible en ligne http:// www.clarin.com/deportes/MUNDIAL_0_920908213.html [consulté le 20 mai 2013] et l'article "Videla, un dictador que quiso tapar sus crímenes con un Mundial de Fútbol", paru dans El Universal, 19 mai 2013, Carthagène des Indes, disponible à l'adresse http:// www.eluniversal.com.co/ cartagena/internacional/videla-un-dictador-que-quiso-tapar-suscrimenes-con-un-mundial-de-futbol-120 [consultéle 20 mai 2013].
} 
Lucie Hémeury, « Entre tribunes et terrain. Les cultures sportives des chefs d’États argentins des années 1880 aux années 1990 », Histoire@Politique. Politique, culture, société, n²3, mai-août 2014 [en ligne, www.histoire-politique.fr]

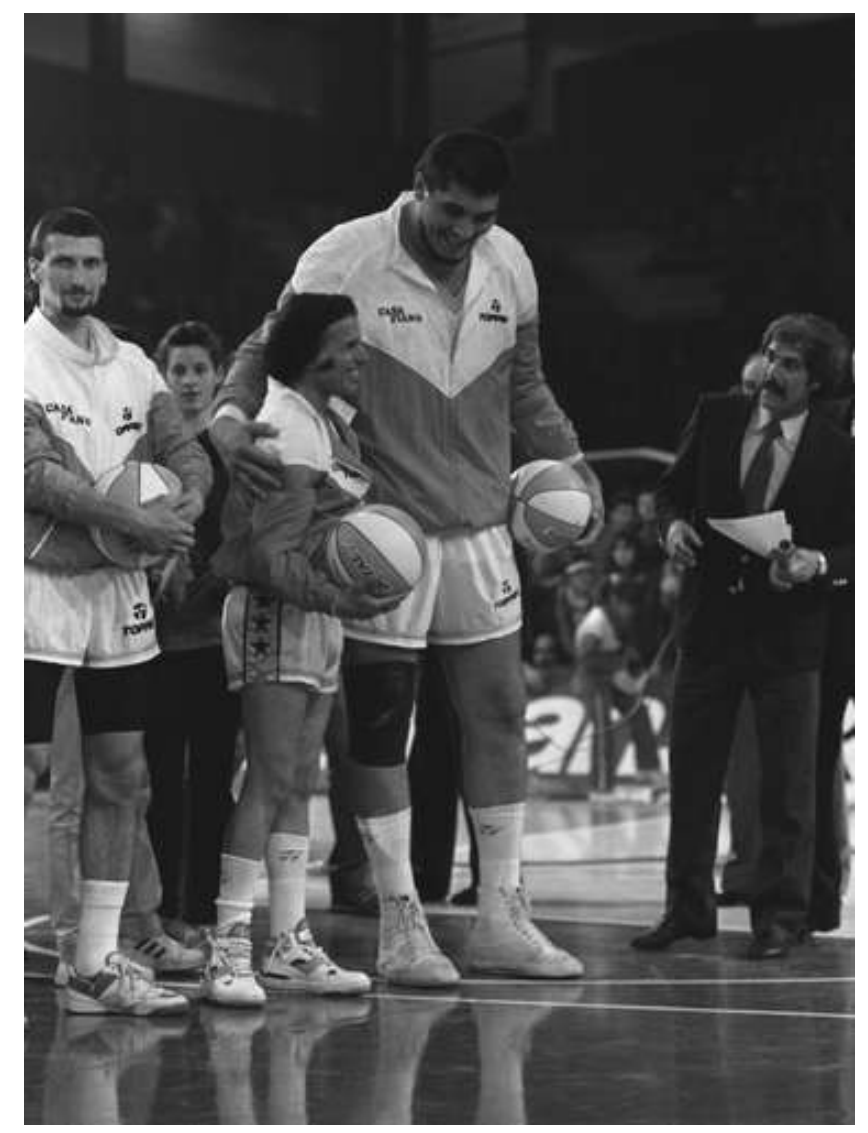

Illustration 6. Carlos Menem participa à un match de basket-ball en 1990 aux côtés de J orge González, un joueur atteint de gigantisme. (C) Droits réservés.

Il rompit avec la figure du président spectateur pour devenir un président participant, occupant le centre de la scène sportive. Le stade n'était plus seulement un lieu où se rapprocher du peuple en partageant une émotion collective depuis les gradins ou la tribune et tester sa cote de popularité ; désormais, le président sportif se donnait à voir directement, devenait le spectacle en lui-même. Peu de temps avant son investiture présidentielle, Menem participa ainsi aux côtés de joueurs professionnels à un match caritatif de football et resta présent sur le terrain pendant toute la durée de la rencontre. Comme l'explicite Roberto Di Giano, «son action marque un nouveau style, une façon nouvelle de faire de la politique, à partir de l'exhibition corporelle sur un terrain de jeu 39 ».

Cet exemple n'en est qu'un parmi d'autres : au cours de son premier mandat, Menem apparut en partenaire de tous les grands sportifs de l'époque. La surenchère de sa médiatisation fit de lui l'un des initiateurs de la « politique spectacle » contemporaine

39 Roberto Di Giano, «Los usos del fútbol en democracia », Efdeportes Revista Digital, an 5, n²6, octobre 2000, p. 1, disponible en ligne sur http:// www.efdeportes.com/ efd26a/ usosfut.htm [consulté le 3 septembre 2012]. 
Lucie Hémeury, « Entre tribunes et terrain. Les cultures sportives des chefs d’États argentins des années 1880 aux années 1990 », Histoire@Politique. Politique, culture, société, n² 23, mai-août 2014 [en ligne, www.histoire-politique.fr]

en Argentine. Mais ce comportement finit par provoquer des réactions moqueuses et critiques $^{40}$, desservant l'image d'homme moderne, dynamique et décontracté qu'il tentait de construire. Malgré cela, les années 1990 furent des années fastes pour le sport argentin, comparables à la période du premier péronisme, entre 1946 et 1955. Outre les succès dans le sport de compétition, Menem relança des politiques sportives ambitieuses, en suivant les traces de Perón. Il obtint ainsi que le championnat du monde de basket-ball ait lieu en Argentine en 1990, championnat déjà accueilli en 1950 sous Perón, tandis qu'en 1995, la ville de Mar del Plata reçut les J eux panaméricains, comme l'avait fait Buenos Aires en 1951¹. La filiation avec Perón en matière sportive fut recherchée dès la campagne électorale de Menem, qui se clôtura au Luna Park par un rassemblement sportif auquel participèrent de nombreux champions de cette époque. À cette occasion, Menem prononça un discours dans lequel il s'engagea à faire renaître les courses de Formule 1 en Argentine. Cette promesse électorale, qu'il respecta, signale que le sport occupait déjà une place de choix dans son programme politique. L'accueil de grandes compétitions et la réintroduction de la discipline dans laquelle s'était illustré Fangio, l'un des héros sportifs argentins, devaient permettre à l'Argentine de reconquérir sa place parmi les grandes nations sportives. Cette politique visait donc à toucher la corde sensible du sentiment national argentin et à restaurer le prestige d'un pays fortement ébranlé par les années de dictature. Ainsi, Menem encouragea également la candidature de Buenos Aires comme siège des Jeux olympiques de 2004 mais, comme Perón cinquante ans avant lui, ne parvint pas à convaincre les dirigeants du Comité international olympique.

Menem avait aussi conscience des retombées positives sur le plan politique en cas de succès sur le plan sportif. Le Mondial de 1978 en avait constitué un bon exemple: l'obtention du titre de champion du monde de football avait eu un impact, bien que temporaire, sur une partie de l'opinion publique argentine. Renouant avec les stratégies de médiatisation élaborées par Justo et Perón, il sut exploiter les possibilités nouvelles offertes par la télévision dans la construction de son image, devenu le principal média de masse depuis les années 1980. Sur le plan de la communication politique, si Perón avait été un homme de radio, Menem fut un homme de télévision. En 1995, à l'âge de 59 ans, alors qu'il était président en exercice, il participa à nouveau à un match de football pour une œuvre caritative aux côtés des joueurs de l'équipe nationale. Le stade réunissait 40000 spectateurs, mais la rencontre fut aussi diffusée en direct à la télévision. Le lendemain, les journaux commentèrent dans leur rubrique sportive la performance et le jeu de Menem. La médiatisation du président sportif était donc démultipliée grâce au petit écran et aux logiques d'interactions entre les médias.

Menem incarna l'homme politique décomplexé, avec toutes ses outrances et ses excès. Si l'exposition de sa vie intime sur la scène publique fut souvent volontaire, elle

\footnotetext{
40 Une rumeur se répandit suite à plusieurs accidents et déboires survenus à des sportifs qui fréquentaient Menem ou venaient de le rencontrer : Menem serait un « porte-poisse ».

41 Voir l'article du journaliste Ezequiel Fernández Moores, «Se acaban los diez años de deporte menemista ¡La hora, referí!», publié dans Página 12, 25 octobre 1990, disponible en ligne sur http:// www.pagina12.com.ar/ 1999/99-10/99-10-25/ bue05.htm [consulté le 5 septembre 2012]. L'article est accompagné de plusieurs photographies montrant les différentes activités sportives de Carlos Menem.
} 
Lucie Hémeury, « Entre tribunes et terrain. Les cultures sportives des chefs d’États argentins des années 1880 aux années 1990 », Histoire@Politique. Politique, culture, société, n² 23, mai-août 2014 [en ligne, www.histoire-politique.fr]

échappa à plusieurs reprises à son contrôle, ce qui explique sans doute pourquoi ses apparitions en tant que président sportif allèrent en diminuant et finirent par se limiter au golf au cours de son dernier mandat. Le sport a été le domaine dans lequel il a recherché au maximum l'identification avec la figure tutélaire de Perón, mais aussi le seul dans lequel elle était possible.

\section{Conclusion}

Dans un pays où le sport - et notamment le football - est devenu relativement rapidement une affaire d'État, la configuration du milieu sportif et de ses relations structurelles avec le pouvoir ont permis à la culture sportive des chefs d'État de se manifester et d'être relayée par les médias. En attestent un certain nombre de pratiques publiques apparues précocement qui ont donné lieu à ce que nous pourrions qualifier de rituels politico-sportifs : les présidents argentins prirent non seulement l'habitude d'apparaître dans les tribunes parmi les spectateurs, mais aussi de descendre sur le terrain, pour donner le coup d'envoi d'un match, pour saluer ou féliciter les joueurs, pour exprimer leur enthousiasme en étreignant le héros du jour et même, avec Menem, pour devenir un membre à part entière de l'équipe.

Le stade et le club ont pu constituer des espaces privilégiés d'intervention, de représentation politique et de communion avec les masses pour les chefs d'État argentins, tout comme ils se sont transformés en lieux de contestation du pouvoir et de rejet de la figure présidentielle impopulaire. Comme dans tout domaine, le leader politique devait apparaître comme légitime aux yeux de l'opinion publique pour pouvoir occuper physiquement et symboliquement l'espace sportif. Seuls ceux qui ont su démontrer, notamment grâce à leur maîtrise des stratégies médiatiques et de l'art de la communication politique, l'authenticité de leur culture sportive et de leur attention au développement des activités sportives y sont parvenus.

\section{Compléments iconographiques}

- Consulter le site de la bibliothèque virtuelle de l'AFA riche en images d'archives digitalisées : http:// biblioteca.afa.org.ar/ galeria.html

- L'enregistrement vidéo de Juan Carlos Onganía jouant au polo, mis en ligne par DiFilm, un groupe spécialisé dans la conservation, la restauration et la commercialisation d'archives audiovisuelles : https:// www.youtube.com/ watch?v=EuGUO9gDJ6k

\section{Bibliographie}

- Angela Aisenstein et Pablo Scharagrodsky, Tras las huellas de la Educación Física Escolar Argentina. Cuerpo, género y pedagogía.1880-1950, Prometeo, Buenos Aires, 2006.

- Pablo Alabarces, Fútbol y Patria, Buenos Aires, Prometeo, 2008.

- Eduardo P. Archetti, "Nationalisme, football et polo : tradition et créolisation dans la construction de l'Argentine moderne", Terrain, n² 25, p. 73-90, 1995. 
Lucie Hémeury, « Entre tribunes et terrain. Les cultures sportives des chefs d’États argentins des années 1880 aux années 1990 », Histoire@Politique. Politique, culture, société, n²3, mai-août 2014 [en ligne, www.histoire-politique.fr]

- Patrick Clastres et Cécile Méadel [coord.], Le Temps des Médias. La fabrique du sport, 2007/2, $\mathrm{n}^{\circ} 8$.

- Roberto Di Giano, «Los usos del fútbol en democracia », EFdeportes Revista Digital, an 5, $n^{\circ} 26$, octobre 2000, disponible en ligne sur http://www.efdeportes.com/efd26a/ usosfut.htm [consulté le 3 septembre 2012].

- Ezequiel Fernández Moores, «Se acaban los diez años de deporte menemista ¡La hora, referí ! », publié dans Página 12, 25 octobre 1990, disponible en ligne sur http://www.pagina12.com.ar/1999/99-10/99-10-25/bue05.htm [consulté le 5 septembre 2012].

- Julio Frydenberg, Historia social del fútbol, Buenos Aires, Siglo XXI Editores, 2011.

- Sandra Gayol, Honor y Duelo en la Argentina moderna, Buenos Aires, Siglo XXI Editores, 2008.

- Víctor Lupo, Historia política del deporte argentino, Buenos Aires, Corregidor, 2004

- Daniele Marchesini, «Corps et pouvoir dans l'Italie fasciste: Mussolini, Carnera et les Italiens », dans Georges Bensoussan, Paul Dietschy, Caroline François et Hubert Strouk, Sport, corps et sociétés de masse. Le projet d'un homme nouveau, Paris, Armand Colin, 2012, p. 93-103.

- Eduardo A. Olivera, Orígenes de los deportes británicos en el Río de la Plata, Buenos Aires, Talleres Gráficos Argentinos, 1932.

- Mariano Plotkin, Mañana es San Perón. A Cultural History of Perón's Argentina, Wilmington (Del.), Scholarly resources, 2003 (1ère édition en espagnol : 1993).

- María Cristina Pons, "Cuerpos sublimes : el deporte en la retórica de la "Nueva Argentina", dans Claudia Soria [et alii], Políticas del Sentimiento. El peronismo y la construcción de la Argentina moderna, Buenos Aires, Prometeo, 2010, p. 49-70.

- Raanan Rein, "El Primer Deportista: The Political Use and Abuse of Sport in Peronist Argentina", International Journal of the History of Sports, 15:2, p. 54-76, 1998.

- Matías Rodríguez, "El Presi también juega", disponible en ligne à l'adresse http:// www.sben.com.ar/sben/2013/11/el-presi-tambien-juega/ [lien consulté le 15juillet 2014].

- Ariel Scher et Héctor Palomino, Fútbol, pasión de multitudes y de elites, Buenos Aires, CISEA, 1989.

- Ariel Scher, La Patria Deportista, Buenos Aires, Editorial Planeta, 1996.

- Ariel Scher, Guillermo Blanco, J orge Busico, Deporte Nacional. Dos siglos de historia, Buenos Aires, Editorial Planeta, 2010

- Richard Slatta, "The Demise of the Gaucho and the Rise of Equestrian Sport in Argentina", J ournal of Sport History, vol. 13, 2, 1986, p. 97-110.

- Georges Vigarello, Du jeu ancien au show sportif. La naissance d'un mythe, Paris, Éditions du Seuil, 2002.

\section{L'auteur}

Lucie Hémeury est doctorante allocataire (Bourse hors DIM Région Île-de-France) en histoire (IHEAL-CREDA UMR 7227, Université Paris 3 - Sorbonne-Nouvelle). Elle consacre ses recherches à l'histoire culturelle, sociale et politique de l'Argentine dans la première moitié du XX ${ }^{\mathrm{e}}$ siècle, et prépare actuellement une thèse consacrée aux 
Lucie Hémeury, « Entre tribunes et terrain. Les cultures sportives des chefs d’États argentins des années 1880 aux années 1990 », Histoire@Politique. Politique, culture, société, n² 23, mai-août 2014 [en ligne, www.histoire-politique.fr]

relations entre sports, médias et péronisme en Argentine entre 1946 et 1955. Elle a notamment publié: « Centaures, sportsmen et gauchos. Les joueurs de polo argentins de l'entre-deux-guerres dans la revue sportive El Gráfico », dans Françoise Bosman, Patrick Clastres et Paul Dietschy (dir.), Images de sport. De l'archive à l'histoire, Paris, Nouveau Monde éditions, 2010 ; « Le pouvoir hors-jeu ? Football et péronisme en Argentine 1946-1955 », dans Cahiers des Amériques latines, Dossier «L'autre continent du football », $\mathrm{n}^{\circ}$ 74, volume 2013/3.

\title{
Résumé
}

Cet article propose une analyse de la culture sportive des chefs d'État argentins entre les années 1880 et 1990. Le sport est devenu un phénomène social, culturel et médiatique massif, face auquel les dirigeants politiques ne sont pas restés indifférents. L'organisation de la Coupe du monde de football en 1978 lors de la dictature la plus violente qu'ait connue l'Argentine est restée dans les mémoires comme un exemple d'instrumentalisation extrême du sport par un pouvoir en quête de légitimité. Mais au-delà de ce cas, les hommes politiques argentins entretinrent des rapports au sport bien plus divers. Sportifs, spectateurs assidus, promoteurs du sport, ils révèlent la complexité à l'œeuvre au sein de la culture sportive argentine au cours du XXe siècle.

Mots clés : histoire ; sport ; Argentine ; chefs d'État ; politique.

\begin{abstract}
"Politics on the Ground: Argentinean Heads of State and Sports Culture from the 1880s to the 1990s"

This article offers an analysis of the sport culture fostered by Argentinean heads of state between the 1880s and the 1990s. Sport became a widespread social and cultural phenomenon that was central in mass media, and statesmen did not remain indifferent to it. The organization of the Football World Cup in 1978, under the most violent dictatorship Argentina ever knew, is still remembered as an example of how sports can be utilized by powerful leaders in quest of legitimacy. However, the links between Argentinean politicians and sports were much more diverse and should not be reduced to the limited scope of the World Cup. As sportsmen, regular spectators or promoters of sports, Argentinean heads of state revealed how complex sporting culture was throughout the 20th century.
\end{abstract}

Keywords : History; Sports; Argentina; Statesmen; Politics.

Pour citer cet article : Lucie Hémeury, « Entre tribunes et terrain. Les cultures sportives des chefs d'États argentins des années 1880 aux années 1990 », Histoire@Politique. Politique, culture, société, n²3, mai-août 2014 [en ligne, www.histoire-politique.fr] 